LETTER TO THE EDITOR

\title{
Should the role of mast cells in chronic rhinosinusitis with nasal polyps be revaluated?
}

\author{
Dovremmo rivalutare il ruolo dei mastociti nella rinosinusite cronica associata \\ a poliposi nasale?
}

Matteo Gelardi, Rossana Giancaspro, Michele Cassano

Department of Otolaryngology, University Hospital of Foggia, Foggia, Italy

KEY WORDS: mast cells, chronic rhinosinusitis with nasal polyps, nasal cytology

PAROLE CHIAVE: mastociti, rinosinusite cronica associata a poliposi nasale, citologia nasale

\section{Dear Editor,}

we read with great interest the study by Kowalik and colleagues concerning the crucial role that the SWI/SNF complex might play in the development and treatment of Chronic Rhinosinusitis (CRS) ${ }^{1}$. In fact, chromatin remodelling in the SWI/SNF complex is involved in transcriptional control, DNA repair, hormonal signalling and inflammation. Moreover, the SWI/SNF complex regulates glucocorticoid receptors and the action of vitamin D by modulating the expression of the vitamin D receptor. In particular, the combination of activated VDR and the SWI/SNF complex promotes anti-inflammatory processes. As shown by the authors, the expression of SWI/SNF occurs in the sinonasal mucosa of both eosinophilic CRS (eCRS) and non-eosinophilic CRS (neCRS), with lower expression in the former. Blood eosinophil count (BEC) and histopathology eosinophil count correlate negatively with all the SWI/SNF subunits and positively with clinical findings, such as Lund-Mackay CT scores and Sino-Nasal Outcome Test (SNOT)-22. Although the inflammatory mechanisms and molecular processes underlying eCRS are still not fully understood, the authors hypothesise that the negative correlation of the SWI/SNF complex with eosinophils may explain the worse prognosis of eCRS, compared to neCRS, and resistance to glucocorticoid treatments. Thus, they emphasise the role of eosinophils in the pathophysiology of CRS, which represent a marker of severity of disease.

Actually, the crucial role that eosinophils play in the pathogenesis of CRS has long been recognised and several biomarkers of eosinophilic inflammation have been identified, including the Charcot-Leyden crystal protein (CLCP) ${ }^{2}$. However, in the era of precision medicine, accurately identifying the different phenotypes and endotypes of chronic respiratory disorders is crucial in order to guarantee therapeutic approaches tailored to each patient ${ }^{3}$. In this context, we would emphasise the role of mast cells (MCs), which are too often underestimated. In fact, even if over the years knowledge of the CRS has increased significantly, most studies have focused attention on eosinophilic or neutrophilic inflammation ${ }^{4}$. Only recently, attention is shifting towards another cytotype, equally involved in the mechanisms underlying CRS, represented by the MC. In particular, MCs, which are probably activated by local IgE, cytokines and chemokines, promote eosinophilic infiltration and tissue remodeling through the degradation of the extracellular matrix ${ }^{5}$.

Received: July 21, 2021

Accepted: September 21, 2021

Correspondence

Rossana Giancaspro

Department of Otolaryngology, University of Foggia, via Luigi Pinto 1, 71122. Foggia, Italy

E-mail: rogianca@live.it

Funding

None

Conflict of interest

The Authors declare no conflict of interest.

How to cite this article: Gelardi M, Giancaspro $\mathrm{R}$, Cassano M. Should the role of mast cells in chronic rhinosinusitis with nasal polyps be revaluated? Acta Otorhinolaryngol Ital 2021;41:576577. https://doi.org/10.14639/0392-100X-N1768

(C) Società Italiana di Otorinolaringoiatria e Chirurgia Cervico-Facciale

\section{cc) (1)}

This is an open access article distributed in accordance with the CC-BY-NC-ND (Creative Commons Attribution-NonCommercial-NoDerivatives 4.0 International) license. The article can be used by giving appropriate credit and mentioning the license, but only for non-commercial purposes and only in the original version. For further information: https:// creativecommons.org/licenses/by-nc-nd/4.0/deed.en 


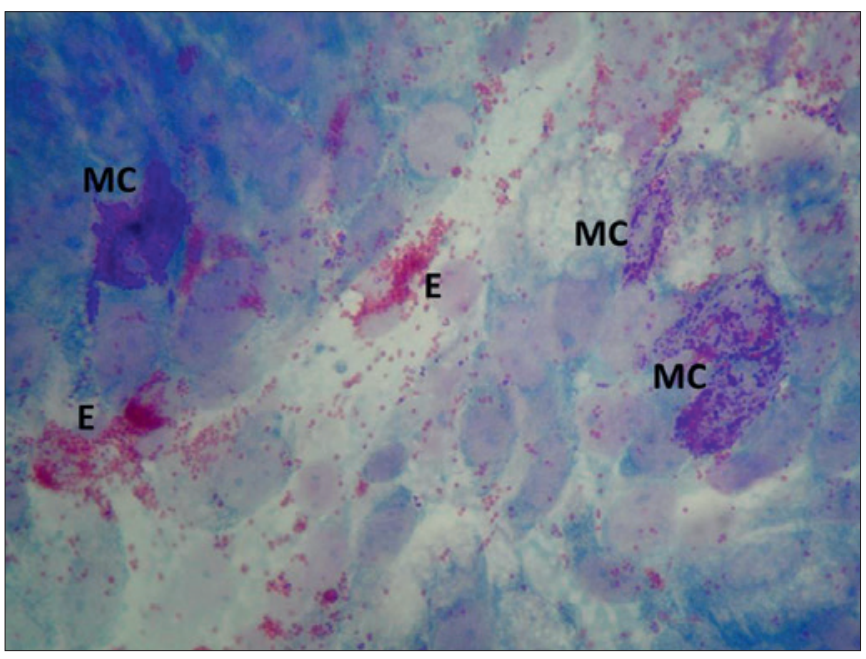

Figure 1. Pathological findings at nasal cytology in CRSwNP.

E: eosinophil; MC: Mast cell. May-Grunwald-Giemsa (MGG) staining. Magnification 1000x.

Furthermore, a recent study has shown that severe asthma and CRS with nasal polyps (CRSwNP), which are frequent comorbidities, are associated with the expansion of intraepithelial MCT, expressing carboxypeptidase A3 (CPA3) and mucosal epithelial MCTC, infiltrating the airway smooth muscle and sub epithelial glandular tissue ${ }^{6}$. These subtypes are involved in the activation of eosinophils and, in particular, the positive correlation between eosinophilia and MC activation in CRS is demonstrated by the increased levels of MCs in nasal polyps of patients with eCRS ${ }^{7}$.

These findings have not only molecular, but also clinical implications. Indeed, our previous studies have shown that inflammatory cytotypes at nasal cytology of patients with CRSwNP are represented prevalently by eosinophils (61.8\%) and by eosinophils-MCs (31.9\%), while MCs and neutrophils are respectively found in $3.5 \%$ and $2.8 \%$ of cases, and that the mixed inflammatory infiltrate is responsible for more severe and difficult to treat forms ${ }^{8,9}$. A Clinical-Cytological Grading (CCG), which is based on both endotype (predominant cytotype at nasal cytology) and phenotype (asthma, allergy and ASA sensitivity), has been proposed to assess the severity of CRSwNP and the Prognostic Index of Relapse. Most severe forms, characterised by a high-grade CCG, are significantly associated with a mixed eosinophilic-MC phenotype, frequent comorbidities and recurrent surgery, especially if accompanied by evident signs of degranulation (Fig. 1) ${ }^{10}$. In addition, our recent studies show a strong correlation between CCG and expression of CLCP, also named as Galectin-10. This biomarker is a major constituent of the cytoplasm of eosinophils and characteristically forms bi-pyramidal hexagonal crystals when eosinophils are intensely activated and undergo ETosis, causing a crystallopathy ${ }^{2}$. Although it has classically been considered the expression of exclusively eosinophilic inflammation, our aforementioned study demonstrates that CLCP-10 also co-localises with MCs. These observations suggest the involvement of MCs in the pathogenesis of CRS and, in particular, in the spectrum of pathologies underlying Type 2 inflammation, such as CRSwNP.

In light of this evidence, although Kowalik and colleagues have clearly shown the correlation between the SWI/SNF complex and eosinophilic inflammation in the pathogenesis of CRS, we believe that the attention of research should no longer focus exclusively on eosinophils, but should turn to the study of other cytotypes, such as MCs. This new cytological point of view could guarantee a specific diagnosis and therefore effective therapy, tailored to the patient's phenotype and endotype.

\section{References}

Kowalik K, Waniewska-Leczycka M, Sarnowska E, et al. The SWI/ SNF complex in eosinophilic and non eosinophilic chronic rhinosinusitis. Acta Otorhinolaryngol Ital 2021;41:159-167. https://doi. org/10.14639/0392-100X-N0760

2 Wu D, Yan B, Wang Y, et al. Predictive significance of charcot-leyden crystal protein in nasal secretions in recurrent chronic rhinosinusitis with nasal polyps. Int Arch Allergy Immunol 2021;182:65-75. https:// doi.org/10.1159/000510120

3 Gallo S, Bandi F, Preti A, et al. Exploring the role of nasal cytology in chronic rhinosinusitis. Acta Otorhinolaryngol Ital 2020;40:368-376. https://doi.org/10.14639/0392-100X-N0711

4 Rosati D, Rosato C, Pagliuca G, et al. Predictive markers of long-term recurrence in chronic rhinosinusitis with nasal polyps. Am J Otolaryngol 2020;41:102286. https://doi.org/10.1016/j.amjoto.2019.102286

5 Zhai GT, Li JX, Zhang XH, et al. Increased accumulation of CD30 ligand-positive mast cells associates with eosinophilic inflammation in nasal polyps. Laryngoscope 2019;129:E110-E117. https://doi. org/10.1002/lary.27658

6 Dwyer DF, Ordovas-Montanes J, Allon SJ, et al. Human airway mast cells proliferate and acquire distinct inflammation-driven phenotypes during type 2 inflammation. Sci Immunol 2021 Feb 26;6:eabb7221. https://doi.org/10.1126/sciimmunol.abb7221

Takabayashi T, Schleimer RP. Formation of nasal polyps: the roles of innate type 2 inflammation and deposition of fibrin. J Allergy Clin Immunol 2020;145:740-750. https://doi.org/10.1016/j.jaci.2020.01.027

8 Gelardi M, Russo C, Fiorella ML, et al. Inflammatory cell types in nasal polyps. Cytopathology 2010;21:201-203. https://doi. org/10.1111/j.1365-2303.2009.00671.x

9 Gelardi M, Porro G, Quaranta N, et al. Clinical-cytological-grading and phenotyping in patients with chronic rhinosinusitis with nasal polyps: the relevance in clinical practice. Monaldi Arch Chest Dis 2020;90:348-352. https://doi.org/10.4081/monaldi.2020.1277

10 Gelardi M, Netti GS, Giancaspro R, et al. Chronic rhinosinusitis with nasal polyposis (CRSwNP): the correlation between expression of Galectin-10 and Clinical-Cytological Grading (CCG). Am J Rhinol Allergy 2021 Oct 14:19458924211049867. https://doi. org/10.1177/19458924211049867 